This item was submitted to Loughborough's Research Repository by the author.

Items in Figshare are protected by copyright, with all rights reserved, unless otherwise indicated.

\title{
Excellent product ... but too early to say: Consumer reactions to tentative product reviews
}

PLEASE CITE THE PUBLISHED VERSION

https://doi.org/10.1016/j.intmar.2020.03.002

PUBLISHER

Elsevier

VERSION

AM (Accepted Manuscript)

\section{PUBLISHER STATEMENT}

This paper was accepted for publication in the journal Journal of Interactive Marketing and the definitive published version is available at https://doi.org/10.1016/j.intmar.2020.03.002.

LICENCE

CC BY-NC-ND 4.0

\section{REPOSITORY RECORD}

Ifie, Kemefasu. 2020. "Excellent Product ... but Too Early to Say: Consumer Reactions to Tentative Product Reviews". Loughborough University. https://hdl.handle.net/2134/12033873.v1. 


\title{
Excellent Product...But Too Early to Say: Consumer Reactions to Tentative Product Reviews
}

\begin{abstract}
This research explores the effects of tentativeness in online product reviews on consumers' product attitude certainty and behavioural intentions. Drawing on salience theory, attribution theory and work in attitude certainty, we predict that, when consumers who have seen positive reviews of a product are exposed to a tentative review, their attitude certainty and willingness to purchase is reduced. We also predict that consumer reactions differ depending the expertise of the review source as well as the product experience of the consumer. We also address confidence in information completeness as the metacognitive mechanism that explains the tentative review effect. Specifically, we argue that consumers who see a tentative review are sensitised to potentially missing information which reduces their attitude certainty and willingness to purchase.
\end{abstract}

The hypotheses are tested in a series of experiments which demonstrate that tentativeness reduces attitude certainty and willingness to purchase, but that the effect is attenuated when the reviewer is a novice and when the consumer has a high level of product experience. Based on the findings, we discuss the contributions to theory and suggest practical steps that firms can take to mitigate the effects of tentative reviews. 
"Excellent product at a very reasonable price. It gets the dishes sparkling clean but it's early days yet.

"My first impressions are that it is a very good product, but it is too early to say how reliable it is.

\section{INTRODUCTION}

In today's competitive landscape, the successes of many products and services depend on online reviews (Floyd et al., 2014). Consumers consult online reviews to reduce the uncertainty associated with making product selection decisions (Mudambi and Schuff 2010). However, in the process, consumers sometimes encounter reviews, (such as those above) where the reviewer, despite providing a positive evaluation, expresses tentativeness about their evaluation. In this paper, we address the notion of tentativeness in online reviews and conceptualise a tentative review as one which, through the use of hedging phrases (ForbesRiley and Litman 2011) such as "it's early days", "too early to say" "we have to wait" etc. suggests that a reviewer's evaluations of a product is not definite and so may change or "become obsolete when more reliable findings occur" (Flemming et al., 2015, p2). While the literature evidences a plethora of studies that have addressed the effects of various contentrelated and style-related elements of online reviews (see Table 1), no previous study has addressed whether and how the expression of tentativeness in online reviews impacts on consumers' attitudes and intentions. Furthermore, assessing whether and how the effect of tentativeness may be distinct from the effect of other related review characteristics such as mixed or ambivalent evaluations is also critical. Accordingly, the key question of interest in this study is whether tentative reviews influence customers' product-related attitudes, 
perceptions and decisions. If so, under what conditions are these effects stronger or weaker and how should firms react to or manage such reviews?

This study draws on salience theory (Taylor and Thompson 1982) as well as studies on attitude certainty (Rucker et al 2008, 2014), to contend that the inclusion of a tentative review to a set of positive reviews should result in lower levels of product-related attitude certainty and purchase intentions compared to the inclusion of a wholly positive review, a negative review, and a mixed review. We propose and theoretically address confidence in information completeness (i.e., consumer's evaluation about the completeness of information they have about an object) (Rucker et al 2014; Shoham et al 2017), as the intermediate cognitive mechanism; we expect that a tentative review will reduce consumers' confidence in the completeness of information they have about a product and ultimately result in lower levels of attitude certainty and purchase intentions. Furthermore, in line with suggestions that the effect of online reviews is moderated by product, reviewer and customer characteristics (Zhu and Zhang 2010; Ho-Dac et al 2013; Casaló et al 2015), we investigate two important moderating effects. First, we draw on the notion that source and message characteristics often interact to determine the efficacy of online reviews and that source characteristics might determine whether and the extent to which information receivers attribute message characteristics to factors other than the product experience (Banarjeee et al., 2017). Consequently, we assess whether cues about the reviewer's expertise (or lack of) will alter the extent to which information receivers attribute review tentativeness to the product versus the reviewer. We expect that tentativeness will be more strongly attributed to the reviewer (than to product-related factors) when the reviewer is seen as a novice thus attenuating the effect of a tentative review. Second, drawing on evidence that novices and experts utilise product-related information differently (Nam, Wang and Lee 2012), we investigate whether 
the effect of a tentative review is contingent upon consumers' product experience. We expect that consumers with more (less) product experience will have a lower (higher) baseline product uncertainty (Lee and Ro 2016) and so will be less (more) sensitive to tentative reviews.

This work contributes to the marketing and consumer behaviour literatures by investigating the effect on consumers of an online review characteristic (tentativeness) which despite its occurrence in product reviews has received no prior attention in the literature. Specifically, we show that a tentative review weakens consumers' attitude certainty and purchase intentions to a stronger extent than mixed and negative reviews. The effect we demonstrate is not an intuitive one and is practically relevant given that brand owners might perceive the effects of a tentative review to be no different from the effects of a positive review. Accordingly, by understanding how tentative reviews impact consumers and in what contexts these effects are strongest, firms can formulate appropriate responses to counter their effect on consumers.

The remainder of the paper is organized as follows. First, we provide a brief general discussion on tentativeness and then specifically address its occurrence in online product reviews. Next, we review the literature on attitude certainty and salience which we build upon in formulating our hypotheses. We then discuss the experiments conducted to test our hypotheses. Finally, we discuss the implications of our findings for theory and practice. 


\section{LITERATURE REVIEW AND HYPOTHESES}

In this section, we discuss the main constructs of interest in this study and present hypotheses linking them. Following that, we present the two moderation hypotheses.

\section{Tentativeness in Online Reviews}

In conceptualising a tentative review, it is important to distinguish among the notions of inherent tentativeness, perceptions of tentativeness, and the expression of tentativeness (Flemming, et al., 2017; Lederman and O’Malley, 1990). The concept of tentativeness has been the subject of significant discourse within the scientific literature (see Schwartz and Lederman, 2008). In this context, tentativeness refers to the idea that conclusions drawn from empirical research are inherently provisional, hardly ever represent definite knowledge and are thus frequently subject to revision (Flemming et al., 2017). Extending this notion to product evaluations, it can be argued, at a very broad level, that many product reviews are to some degree inherently tentative since consumers can (and sometimes do) revise their product evaluations as they gain more experience with a product or service (Hassan et al., 2018) or engage in deeper reflection (Häfner and Trampe 2009). Some review sites have begun to account for this by allowing reviewers to revise their product evaluations as they gain more experience with a product (Chevalier et al., 2018; Hassan et al., 2018).

Perceived tentativeness refers to the extent to which either a reviewer or an observer perceives a review to be tentative (Snehasish 2017). For example, customers providing realtime evaluations (Poddar, Banerjee and Sridhar 2017) or evaluations immediately after a purchase may feel that their evaluation is tentative because the experiential foundation for it is weak. However, consumers may not often express their tentativeness in a review. Customers who consult reviews can also use various cues to judge a review's tentativeness. 
For instance, temporal contiguity cues (i.e., cues that suggest reviews have been provided during or very quickly after purchase of a product) could theoretically lead to stronger attributions about review tentativeness (see Wu et al., 2017). However, for many customers, judgements about review tentativeness may only come to the fore when tentativeness is explicitly expressed in a review (Flemming et al., 2017).

The focus in this study is on expressed tentativeness; i.e. tentativeness that is explicitly conveyed in a product review. We define a tentative review as one which, through the use of hedging phrases (Forbes-Riley and Litman 2011) such as "it's early days", "too early to say" "we have to wait" etc. suggests that a consumer's evaluations of a product could change or "become obsolete when more reliable findings occur" (Flemming et al., 2015 p2). The extant literature suggests two broad motivations for expressing tentativeness: when there is 1) a lack of complete commitment to the reality of a proposition and/or 2) a desire for not expressing commitment to a proposition (Hyland 1996). It is possible that this desire may be driven by risk aversion, the need to protect one's reputation or even an attempt to be objective or to appear complete in an evaluation. While, we acknowledge these issues, this study does not address these underlying reviewer motivations. Our proposition is that regardless of the reviewer's motivation, the expression of tentativeness creates a sense in the observer that the information needed for decision-making and attitude formation is incomplete.

Tentative reviews are more common in reviews of physical goods. They are also found in services that are expected to be consumed over a period, i.e. continuous services. Although, there are examples of tentative reviews in discrete services, these occur less frequently. Tentative product reviews also generally tend to be positively valenced. Consistent with the idea that negative initial impressions are more stable, i.e., fade much more slowly than 
positive ones (Skowronski and Carlston 1989), it is more likely for consumers to believe and thus express that a positive experience with a product may not be guaranteed in the long-term than to expect and explicitly suggest, after having a negative experience, that future experiences might be positive. Our study thus focuses on tentative reviews that are positive.

Finally, it is important here to emphasise the conceptual distinction between tentative reviews and mixed reviews. While mixed or ambivalent reviews contain both positive and negative evaluations (Tang et al 2014), tentative reviews are positive, albeit tentatively expressed reviews. We expect the effect of a tentative review to be distinct from that of a mixed review and address this conceptually in our hypothesis as well as empirically with an experiment.

\section{Attitude Certainty}

The importance of consumers' product attitudes in driving behavior has been recognized by consumer researchers for decades (Sheppard, Jon, and Warshaw, 1988; Ajzen, 1991; Petty and Briñol 2008). More recently, consumer psychologists have argued for the inclusion of attitude certainty as a key driver of consumer behavior (Tormala and Rucker 2018; Rucker et al 2014). Attitude certainty is a metacognitive assessment that refers to the subjective sense of conviction an individual has about his or her attitude (Rucker et al 2014). Attitudes held with high certainty are more likely to influence behavior (Tormala and Rucker 2018). For instance, extant research shows that customers who are more certain about their product attitudes may reduce their search time, be less willing to consider alternatives, be more likely to purchase products (Wan et al., 2010), be more likely to repurchase (Choi and Mattila, 2018), engage in advocacy, focus more on attitude-congruent rather than attitude-incongruent 
information; evaluate product quality more positively and purchase more quickly (Shoham et al., 2017). These outcomes are clearly beneficial for brand owners.

Attitude certainty is related to the information upon which an attitude is based, the way the information is acquired, as well as the information source (Rucker et al, 2014; Tormala and Rucker, 2018). Primarily, attitude certainty is driven by a set of appraisals related to the accuracy, completeness, relevance, legitimacy, and importance of the evidence upon which an attitude is founded (see Rucker, 2014 for a full review). These psychological appraisals are themselves underpinned by a number of key variables. Of importance in this study is the appraisal of information completeness which we discuss next.

\section{Confidence in Information Completeness}

Confidence in information completeness refers to the extent to which a consumer believes that the information they have about an object is complete (Rucker et al., 2014; Shoham et al., 2017). Confidence in information completeness is not a personality trait and relates only to the evaluation of contextual information. As such, it is distinct from individual difference variables such as need for cognition and need for cognitive closure (which although can vary as a function of the situation) are personality traits (Cacioppo, Petty, and Kao 1984; Webster and Kruglanski 1994).

Two important factors that create a sense of information completeness are 1) whether the information considers both the pros and cons of an attitude object and 2) the amount of information a consumer has. First, information completeness is enhanced when consumers feel they have considered both the pros and cons of an attitude object (Rucker, Petty, and 
Brinol 2008). For instance, when exposed to positive product reviews, consumers have been known to seek out negative or mixed reviews in order to gain a sense of completeness about the information upon which to form their attitudes. Second, a greater amount of information signals that there are fewer unknowns that might disconfirm an attitude, and thus strengthens the conviction with which consumers hold the attitude (Smith et al., 2008). However, a lot of information does not mean that the evidence underpinning attitudes is strong. Very often, consumers, by considering only information that is presented (e.g., in reviews) and ignoring or not considering information that is not provided, base their product attitudes on weak evidence However, consumers can be sensitised to missing information and when this occurs, their sense of information completeness and consequently their certainty about their attitudes as well as their intentions towards the product is diminished (Kardes et al., 2006) .

\section{Using Tentative Reviews to Form Product Attitudes}

In this paper, we examine how a tentative review that appear alongside positive product reviews impact consumers' certainty about product quality. This approach is consistent with recent research which shows that the influence of online reviews is affected by other reviews that appear alongside them (Ludwig et al., 2013; Tang et al., 2014; Shoham et al., 2017).

Consumers feel more certain about their attitude towards products when they have more information about them. Based on this idea, an additional review which confirms previous information or provides new information should result in greater levels of attitude certainty (Rucker et al., 2014). We argue, however, that despite being positive, a tentative review should weaken consumers' confidence in the completeness of the information they have. This contention is consistent with the cognitive underpinning of salience theory i.e., that "when one's attention is differentially directed to one portion of the environment rather than to others, 
the information contained in that portion will receive disproportionate weighting in subsequent judgments" (Taylor and Thompson, 1982:175). We suggest that, because of its non-committal nature, a tentative review draws attentional focus away from what is known (i.e. product information contained in the reviews) and towards what may be potentially unknown about the product. Put differently, a tentative review sensitises consumers to potentially missing information (Kardes et al., 2006; Pfeiffer et al., 2014) related to the long-term performance of the product. As such, consumers who are exposed to a tentative review may feel that they have not considered some relevant product information and therefore that more information is needed to formulate their product attitude with greater certainty. Hence, we hypothesise:

H1. When consumers view a set of positive product reviews, the addition of a tentative review will result in a lower level of certainty about product quality compared to the inclusion of:
a. No additional review
b. A positive (non-tentative) review.
c. A negative review

H1d. When consumers view a set of positive product reviews, the addition of a tentative review will result in weaker purchase intentions compared to the inclusion of a mixed review

$\mathrm{H} 2$ : Confidence in the completeness of the information will mediate the effect.

\section{The Moderating Role of Source Expertise}

Perceptions of source credibility stem from expertise or trustworthiness or a combination of both (McGinnies and Ward, 1980). Rucker et al (2014) suggest that to better understand how 
source credibility affects attitude certainty, it is important to understand the specific appraisals it stimulates. In this study, we argue that source expertise impacts on attitude certainty by affecting consumers' confidence in the completeness of information.

Previous research has shown that consumers attribute claims in online reviews to reviewers' preferences and/or the actual characteristics of the product (Qui et al., 2012; Sen and Lerman, 2007) and that the type of attributions consumers make will depend on how credible they perceive the source to be. When there is no evidence to the contrary, consumers who see online product reviews often perceive reviewers as reasonably knowledgeable about the product they are reviewing (Banarjee et al., 2017; Jensen et al., 2013). As such they tend to focus their attention on product-related information. However, when there is explicit information about the reviewer's lack of expertise, consumer attributions should become increasingly more reviewer-related. This is in line with previous research which shows that consumers often discount reviews from novices, considering them to be less rational (Folse et al., 2016). In the context of this study, we suggest that consumers should attribute the tentativeness expressed by a novice to lack of product experience rather than product-related issues. Hence, consumers will perceive tentativeness displayed by a novice as less relevant and, consequently, less diagnostic for forming their product attitudes. Put more formally,

H3: The negative effect of a tentative review on consumer certainty about product quality will be attenuated when the review is provided by a novice

\section{The Moderating Role of Customers' Product Experience}

Consumers' product experience refers to their knowledge about and familiarity with a product or product category (Alba and Hutchinson, 1987). Consumers' previous experience is a key 
factor that influences how they process product information (e.g., Nam, Wand and Lee 2012). When internal information is unavailable, external information becomes especially relevant to inform customers' product attitudes (Babić et al., 2016). Customers with little productrelated experience are often more uncertain about a product than those with greater experience. Their product attitudes are thus more susceptible to being reinforced, maintained or attenuated by online product reviews, (Minnema et al., 2016; Lee and Ro, 2016).

In effect, compared to experienced consumers, individual reviews can potentially sway the perceptions and attitudes of inexperienced consumers to a much greater extent. Experienced consumers rely more on their own experiences, are more spontaneously sensitive to omissions (Kardes et al., 2006) and thus, less likely to draw product-related causal inferences from tentative reviews (Chiou et al., 2018). Accordingly, we expect that, when less experienced consumers encounter a tentative review, they should attach a greater weight (than more experienced consumers) to its potential implications, i.e. missing information. Hence, we hypothesise:

H4: The negative effect of a tentative review on certainty about product quality will be attenuated (strengthened) when customer product experience is high (low)

\section{METHODOLOGY}

We test our predictions in five experiments. Study 1 and $1 \mathrm{~b}$ jointly test hypothesis 1 while study 2 demonstrates the proposed underlying mechanism: confidence in information completeness. Study 3 explores the moderating role of source expertise while study 4 investigates the moderating role of customers' product experience. 


\section{Study 1a: The Tentative Review Effect}

The goal of this experiment was to establish the tentative review effect by testing whether exposure to a tentative online review affects consumers' attitude certainty. We predicted that product attitude certainty is weaker when a review set also contains a tentative review compared to three other scenarios where there is no tentative review.

Method

One hundred and fifty-five adults ( 80 females; average age $=28.6$ years, $\mathrm{SD}=7.66$ ) on a UK University campus participated in the experiment. In determining the number and ratio of reviews to use for our experiments, we followed precedents from previous research (e.g., Shoham et al., 2017). Participants were randomly assigned to one of five conditions: a review set with four positive reviews and either (1) a tentative review: "we'll have to wait to see" (2) another tentative review with a different expression: "too early to say", (3) the same review without the tentative element (4) a negative review 5) no additional review (control) (see appendix for stimulus). We used two different tentative phrases with the expectation that they would show convergent effects and thus tentativeness is what matters, not the way it is expressed. There were no significant differences between the two tentative review conditions $(\mathrm{M} 1=4.38$ versus $\mathrm{M} 2=4.40, \mathrm{p}=0.95)$, so we combined them to arrive at a four-condition design.

Participants were asked to imagine that they were interested in buying a dishwasher from an unspecified leading brand and were provided with brief user reviews drawn from an online 
shopping website (similar to Shoham et al., 2017, who also presented participants with several short reviews). The average rating was shown as 4.5 stars (out of five). Four positive reviews (one four-star and three five-star reviews) were the same for all conditions, referring to attributes such as a washing time, drying quality, and the lack of noise. The additional review was listed fourth in the experimental conditions.

After reading the reviews, participants reported their attitudes toward the dishwasher on a 7point scale (“unfavorable/favorable,". To assess attitude certainty, participants were asked to answer the question: "How certain are you about your attitude" (on a 7-point scale of not at all to extremely). As a manipulation check, participants in the additional review conditions rated their agreement. They then rated the additional reviews' tentativeness with the following statements: "the reviewer is uncertain about the product" and "The review is tentative" $(\alpha$ $=.88)$ (tentativeness manipulation check) on a 7-point scale (strongly disagree to strongly agree) and whether the review was positive or negative (on a scale of very negative to very positive (valence manipulation check).

Results

Independent-samples t-tests confirmed that those in the tentative review condition more strongly agreed that the additional review was tentative than those in the two non-tentative conditions $($ Mean Tentative $=5.66$, Mean Non-tentative $=2.29, \mathrm{t}(130)=-6.69 \mathrm{p}<.001)$. The valence manipulation checks also showed that the positive and tentative reviews were both perceived as positive ( $\mathrm{M}$ Tentative: 5.24; $\mathrm{M}$ Non-tentative $=5.92$ and the negative review as negative $($ Mean $=1.47)$. 
A one-way ANOVA showed that participants in the four conditions differed significantly in their reported attitudes $(\mathrm{F}(3,151)=6.89, \mathrm{p}<.05)$. There was no difference between the control condition and the positive non-tentative review. Attitudes in these conditions were however significantly different from the other two conditions. In addition, product attitude was marginally higher for the tentative versus the negative review condition $(p=0.10)$

As predicted in H1, a one-way ANOVA showed that attitude certainty differed across the conditions $(\mathrm{F}(3,151)=10.55, \mathrm{p}<.05)$. In line with $\mathrm{H} 1 \mathrm{a}$ and $\mathrm{H} 1 \mathrm{~b}$, the results revealed that attitude certainty was significantly lower in the tentative review condition $(\mathrm{M}=4.39, \mathrm{SD}=$ 1.02) compared to the non-tentative $(\mathrm{M}=5.22, \mathrm{SD}=0.91 ; \mathrm{t}(151)=-3.96, \mathrm{p}=.00)$ and control conditions $(\mathrm{M}=5.36, \mathrm{SD}=0.94 ; \mathrm{t}(151)=-3.94, \mathrm{p}=.01)$. Attitude certainty in both the positive non-tentative and control conditions also differed significantly from the negative review condition $(p=.00 ; p=0.00)$. There was no significant difference between the nontentative and control conditions $(\mathrm{p}=0.49)$. We received partial support for $\mathrm{H} 1 \mathrm{c}$ in that attitude certainty was lower in the tentative than in the negative review condition (Mean 4.39 versus 4.61). However, the difference was only marginally significant $(\mathrm{p}=0.08)$. Results from the ANOVA are contained in the appendix

\section{Study 1b: Differentiating a Tentative Review from a Mixed Review.}

This experiment served three purposes. First, to distinguish a tentative review from a mixed review (hypothesis 1d). Second, to link tentativeness to a more direct construct: purchase intention and third, to test the effect of tentativeness in a different context: services 


\section{Method}

Ninety adults ( 50 females; average age $=25.8$ years, $\mathrm{SD}=3.66$ ) on a UK University campus participated in the experiment. They were randomly assigned to one of three conditions: a review set with four positive reviews and an additional review which was either (1) a positive review (2) a tentative review or (3) a mixed review. Prior to the experiment we conducted a pilot test with 30 respondents to test that the mixed review was perceived as mixed, rather than as negative. 26 out of 30 respondents scored the review on the midpoint of the scale providing support for it being a mixed neutral review (see Tang et al., 2014).

Participants were asked to imagine that they were interested in visiting a restaurant for a meal with friends for a special occasion and were provided with brief user reviews adapted from a popular review site (see appendix D for stimulus). After reading the reviews, participants reported their intention to visit on a 7-point scale ("very unlikely/very likely,"), their confidence in information completeness and the manipulation checks.

\section{Results}

A one-way ANOVA showed that purchase intentions differed across the conditions $(\mathrm{F}(2,87)$ $=12.05, \mathrm{p}=0.00)$. Purchase intention was significantly lower when the set contained a tentative review $(\mathrm{M}=5.33, \mathrm{SD}=0.99)$ compared to when it included a mixed review $(\mathrm{M}=$ $5.86, \mathrm{SD}=.93 ; \mathrm{t}(58)=-2.138, \mathrm{p}=.03)$ as well as when it included the positive review $(\mathrm{M}=$ $6.46, \mathrm{~S} . \mathrm{D}=0.73 \mathrm{t}(58)=-5.03, \mathrm{p}=0.00)$. The difference between the mixed review and positive review conditions was also significant $(\mathrm{t}(58)=-2.74 ; \mathrm{p}=0.08)$.

The results also revealed that confidence in information completeness was lower when the set contained a tentative review $(\mathrm{M}=4.10, \mathrm{SD}=0.88)$ compared to when it included a mixed 
review $(\mathrm{M}=4.66, \mathrm{SD}=1.06 ; \mathrm{t}(58)=-2.24, \mathrm{p}=.03)$. or a positive review $(\mathrm{M}=4.70, \mathrm{SD}=1.20$ $\mathrm{t}(58)=-2.19, \mathrm{p}=.03)$. There was no significant difference in evaluations of confidence in information completeness between the positive and mixed review conditions $(p=0.91)$

Taken, together the results from these two studies provide support for a distinct negative effect of tentative reviews on information completeness and purchase intentions. Study $1 \mathrm{~b}$ also specifically establishes the effect of a tentative review as distinct from the effect of a mixed review. We explore the underlying mechanism of these effects in the next study.

\section{Study 2: The Mediating Role of Confidence in Information Completeness}

Building on the argument that a tentative review diminishes consumers' confidence in the completeness of the information they have obtained, we formally hypothesised that confidence in information completeness would mediate the effect of a tentative review on attitude certainty. Study 2 tests this proposed metacognitive process.

\section{Method}

117 respondents from English-speaking countries (64 females; Mean Age=33) were recruited and paid $£ 1$ each to participate in an online survey via the data collection website Prolific Academic. We used a similar design to the first study. The only difference was that participants were assigned to one of three conditions: a review set with a tentative review, one with a negative review and another that included a positive non-tentative review.

After reporting their attitudes and attitude certainty, participants rated how confident they were regarding the completeness of the product information they had, with the following 
items "I feel confident that I have a complete picture regarding the dishwasher" and "I need more information to evaluate the dishwasher" (reverse coded) $(\alpha=.85)$. All items were measured on a 7 -point scale $(1=$ strongly disagree, very uncertain; 7 = strongly agree; very certain). They then completed the manipulation checks as in study 1 .

\section{Results}

In line with $\mathrm{H} 1$ and the results of the first study, a one-way ANOVA showed that attitude certainty differed across the conditions $(\mathrm{F}(2,114)=5.64, \mathrm{p}=0.02)$. It was lower when the set contained a tentative review $(\mathrm{M}=4.23, \mathrm{SD}=0.99)$ compared to when it included a nontentative positive review $(\mathrm{M}=5.27, \mathrm{SD}=.93 ; \mathrm{t}(114)=-5.85, \mathrm{p}=00)$ as well as when it included the negative review $(\mathrm{M}=4.69, \mathrm{~S} . \mathrm{D}=0.47 \mathrm{t}(114)=-2.25, \mathrm{p}=02)$. There was also a significant difference between the positive and negative conditions $(t(114)=2.74 ; \mathrm{p}=0.02)$.

Furthermore, as hypothesised, confidence in information completeness was lower when the set contained a tentative review $(\mathrm{M}=3.29, \mathrm{SD}=1.25)$ compared to when it included a nontentative positive review $(\mathrm{M}=4.47, \mathrm{SD}=.75 ; \mathrm{t}(114)=-5.128, \mathrm{p}=.00)$. It was also significantly lower in the tentative review condition compared to the negative review condition $(\mathrm{M}=4.03, \mathrm{SD}=1.18 \mathrm{t}(114)=-2.83, \mathrm{p}=01)$. There was no significant difference in evaluations of confidence in information completeness between the positive and negative conditions $(\mathrm{p}=0.18)$

To test the mediation effect, we used the PROCESS model 4 in SPSS (Hayes, 2013; Preacher, Rucker, and Hayes, 2007) with 5000 bootstrapping samples. Review type was the independent variable (coded as $0=$ tentative, $1=$ non-tentative and $2=$ negative) and confidence in information completeness as the mediator. As predicted in $\mathrm{H} 2$, the effect of 
review type on attitude certainty was mediated by confidence in information completeness (b tentative versus positive non-tentative $=0.20, \mathrm{SE}=0.09 ; 95 \% \mathrm{CI}: 0.04$ to 0.38$)$ and (b (tentative versus negative $=.0 .12, \mathrm{SE}=0.08 ; 95 \% \mathrm{CI}: 0.02$ to 0.31 ).

\section{Study 3: The Moderating Role of Source Expertise}

Earlier, we suggested that there may be conditions under which the tentative review effect may be minimised or enhanced. This study was intended to test if the effect of a tentative review is affected when consumers are made aware of the product-related expertise of the tentative reviewer. We designed Study 3 to test the moderating role of source expertise $(\mathrm{H} 3)$. We expect the tentative review effect to be much weaker when the reviewer self-identifies as a novice. In other words, we expect the effect of a tentative review provided by a novice to be similar to the effect of a non-tentative review.

\section{Method}

The protocol was similar to studies 1 and 2 . However, in this case, the product was a camera drone. 120 university students $(72$ males, mean age $=20.48, \mathrm{SD}=1.10)$ participated in an online study. They were randomly assigned to one of four conditions in a 2 (review type: tentative versus non-tentative) $\times 2$ (review source: novice versus no reviewer information) design. The review by the novice was qualified with the phrase: "It's my first drone". The phrase for tentativeness was "it's too early to say how good this camera drone is"

After reading the reviews, participants rated their attitudes and attitude certainty and then completed the manipulation checks. Reviewer expertise was measured with two items: "This 
reviewer knows a lot about drones" and "the reviewer has a lot of experience with drones" $(\alpha$ $=.86)$.

\section{Results}

The manipulation checks showed that the tentative review was perceived as more tentative than the non-tentative review (M: 5.80 versus M: 2.55). Expertise ratings were also higher in the no-reviewer information compared to the novice condition (M: 4.50 versus M: 2.47).

A $2 \times 2$ ANOVA with source expertise (no-information versus novice) and the two review types (tentative versus non-tentative) as independent variables showed the hypothesised interaction effect $(\mathrm{F}(1,116)=6.30, \mathrm{p}=0.01)$ (see Figure 1). Attitude certainty was significantly higher when the reviewer was a novice $(\mathrm{M}=5.46, \mathrm{SD}=0.78)$ versus when there was no source information $(\mathrm{M}=5.02, \mathrm{SD}=0.85 ; \mathrm{F}(1,116)=5.55, \mathrm{p}=0.02)$. Attitude certainty was also significantly lower for the tentative $(\mathrm{M}=5.07, \mathrm{SD}=1.02)$ compared to the non-tentative reviews $(\mathrm{M}=5.41, \mathrm{SD}=0.66 ; \mathrm{F}(1,116)=4.42, \mathrm{p}=0.04)$.

Planned contrasts showed that in the no source information conditions, attitude certainty was significantly higher when participants saw a non-tentative review $(\mathrm{M}=5.42, \mathrm{SD}=.59)$ than when they saw a tentative review $(\mathrm{M}=4.62, \mathrm{SD}=1.02, \mathrm{~F}=9.90)$. For the novice reviewer conditions, the reverse occurred; attitude certainty was higher for the tentative review condition $(\mathrm{M}=5.52, \mathrm{SD}=.84)$ compared to the non-tentative review $((\mathrm{M}=5.40, \mathrm{SD}=.75)$. However, the difference was not significant $(\mathrm{F}=0.92)$. Attitude certainty did not also differ significantly between the novice conditions and the non-tentative control condition $(\mathrm{F}=0.89)$.

\section{Insert figure 1 here}




\section{Study 4: The Moderating Role of Product Experience}

Earlier we suggested that consumers' knowledge about or experience with a product can affect how they respond to a tentative review. We designed Study 4 to test the moderating role of consumer experience (H4). We expect the tentative review effect to be attenuated when the customer has a greater level of product experience.

Method

Ninety-eight adults (Average age $=30.4$ years, $\mathrm{SD}=5.66$ ) on a UK University campus participated in an online experiment. They were randomly assigned to one of two conditions: a review set with a tentative review and a set with a non-tentative review. Since we were interested in consumer product experience, we chose a product category where we would be able to get a significant variation in product experience (Mitchell and Dacin, 1996).

Participants were asked to imagine that they were interested in buying a wireless phone charger from an unspecified leading brand and were provided with brief user reviews. After reading the reviews, they reported their attitude certainty and level of product experience measured with two items from Mishra et al (1993) "I have a lot of experience with wireless chargers" and "Compared with average person, I know a lot about wireless chargers" $(\alpha$ $=.81)$. Following this, they completed the manipulation check for tentativeness. We averaged the scores on both items for product experience and split consumers into high and low product experience groups using the mean (4.12). The high experience group had 44 respondents (Mean: 5.56, S.D: 0.75) and the low experience group had 54 respondents (Mean: 2.94, SD: 1.15) 
Results

The manipulation checks showed that respondents perceived the tentative review as more tentative than the non-tentative one (M: 5.50 versus M: 2.48). We conducted a $2 \times 2$ ANOVA with customer product experience and review type as the independent variables and attitude certainty as the dependent variable.

Customer product experience had a significant effect on attitude certainty; attitude certainty was higher when the customer had more product experience $(\mathrm{M}=5.51, \mathrm{SD}=$ $.72)$ versus when product experience was low $(\mathrm{M}=5.02, \mathrm{SD}=0.92 ; \mathrm{F}(1,94)=9.15, \mathrm{p}=.00)$. Attitude certainty was also significantly lower for the tentative $(\mathrm{M}=5.01, \mathrm{SD}=1.05)$ compared to non-tentative review $(\mathrm{M}=5.46, \mathrm{SD}=.59 ; \mathrm{F}(1,94)=6.42, \mathrm{p}=0.01)$. In line with $\mathrm{H} 4$, there was also a significant two-way interaction between review type and customer product experience $(\mathrm{F}(1,94)=7.19, \mathrm{p}=0.01)$. Results are shown in Figure 2 below.

\section{Insert Figure 2 here}

Planned contrasts showed no significant difference in attitude certainty between the tentative $(\mathrm{M}=5.52, \mathrm{SD}=.88)$ and non-tentative conditions $(\mathrm{M}=5.50, \mathrm{SD}=.60 ; \mathrm{F}=0.55)$ when product experience was high. However, when product experience was low, there was a significant difference between the tentative $(\mathrm{M}=4.50, \mathrm{SD}=1.03)$ and non-tentative conditions $(\mathrm{M}=5.42, \mathrm{SD}=.59 ; \mathrm{F}=13.14)$. Attitude certainty did not differ significantly between the two high-experience and the non-tentative low experience conditions $(\mathrm{F}=0.88)$. 


\section{GENERAL DISCUSSION}

This study shows that tentativeness in a positive review diminishes consumers' confidence in information completeness, attitude certainty and, willingness to purchase and that reviewer expertise and customer product experience moderate the effect of a tentative review.

Before we discuss how this study contributes to theory and business practice, it is important to ask whether and when consumers are likely to encounter tentative reviews. Furthermore, another question of interest is whether and how tentativeness might relate to the key metric used on review sites to judge online reviews: review helpfulness. These issues are addressed through a supplementary study described in Appendix A. The results show that tentative reviews are in the minority of product reviews (see Appendix A). Given this low prevalence, clearly, for popular, established products with many reviews, one can argue that consumers may be less likely to encounter them and thus they might be less sensitive to the presence of one tentative review alongside many positive reviews. However, most products do not have very many reviews. Recent studies (e.g., Koçaş, and Akkan, 2016; Anderson, 2007) show that the internet has created a "long-tail" effect in many retail environments i.e., a shift away from a relatively small number of "blockbuster" products (with many reviews) to a larger number of niche products (with very few reviews). For instance, McAuley, Pandey, and Leskovec's (2015) dataset of Amazon reviews of 9.35 million items, indicates an average of 15.4 reviews per item with many products having fewer than 10 reviews.

Furthermore, the supplementary analysis shows that tentative reviews are relatively more prevalent among the earlier reviews of a product, when product knowledge might be limited (See Appendix A). Accordingly, for many products, there is a significant chance of 
encountering and being influenced by tentative reviews. This is further backed up by our findings using secondary data which show that tentative reviews are over-represented among reviews that had a 'helpful' vote (Appendix A).

Our central argument, therefore, is that, just as review characteristics that are very prevalent (e.g., negative valence) as well as those which are less prevalent (e.g., temporal contiguity, irrelevant information etc.) can affect consumers, whenever consumers are exposed to a tentative review, their product attitude and willingness to purchase are affected. By studying the effect of tentative reviews in a review set, rather than in isolation, we account for the potential contexts in which customers might encounter them in real-world situations and demonstrate that consumers are sensitive to their presence.

\section{Theoretical Contributions}

This research contributes to the marketing literature in a few important ways. First, we contribute to research that investigates how online reviews characteristics affect consumers. We introduce the notion of expressed tentativeness and show its effects on two important outcomes: attitude certainty and willingness to purchase. In addition to investigating how tentative reviews influence purchase intentions, establishing its effect on attitude certainty is equally crucial as attitude certainty has been shown to drive a variety important consumer behaviours such as search time, advocacy and motivation to process information (Choi and Mattila, 2018; Shoham et al., 2017; Wan et al., 2010). By focusing on both an attitudinal and a behavioural outcome and by testing our hypotheses in both product and service contexts, we highlight the importance of review tentativeness in informing consumer reactions. 
We also investigate the cognitive mechanism-information completeness- that underlies our effects. Online reviews rarely provide a complete picture of a product or service. Nevertheless, consumers rely on them to ascertain if they have enough information to build their attitudes and product choices (Kardes et al., 2006). We find that, when exposed to a tentative review, customers question the completeness of information they have about a product. Put differently, when a tentative review is added to a set of positive reviews, the tentative review weakens confidence in information completeness by discounting, rather than enhancing, the evidence contained in the positive reviews. Therefore, while tentative reviews may be perceived by firms and even customers as no different from other positive reviews, the effects we find in this study suggest otherwise.

In highlighting these effects, we show specifically that the effect of a tentative review is distinct from that of a mixed review. This is a particularly noteworthy insight because it suggests, despite the conceptual similarities between both types of reviews, that the inference consumers draw from a mixed review differs from that drawn from a tentative review. While the presence of a mixed review, (compared to an additional positive one), in a set of positive reviews weakens purchase intentions without significantly affecting confidence in information completeness, a tentative review (compared to both positive and mixed reviews), significantly weakens both confidence in the completeness of information and purchase intentions. It seems that a mixed review does not trigger a sense of missing information and therefore a need for additional information in the manner that a tentative review does.

This paper also contributes to understanding the effect of source and receiver characteristics on consumers' assessment of online reviews. Our finding with respect to the moderating 
effect of reviewer expertise is broadly consistent with extant research on how source certainty and source expertise interact to influence consumer reactions (Karmarkar and Tormala, 2009). We show that the effect of a tentative review is attenuated when tentativeness is congruent with source expertise (i.e., tentativeness is expressed by a novice). Finally, this research contributes to the expertise literature by demonstrating yet another way in which novices and experts utilise and assess information differently. We show that customers are not uniformly influenced by tentative reviews; customers' product experience shapes the effect on a tentative review on attitude certainty. novices who lack product experience are more likely to be swayed by a tentative review.

\section{Implications for Practice}

The effect we demonstrate in this study is not one that firms may naturally consider since they may treat a tentative review just like any other positive review. However, it is important that marketers recognize the gap between their expectations and the reality in terms of the inferences that consumers might draw when exposed to tentative reviews; inferences that have real consequences for consumers attitudes and behaviours. For instance, although tentative reviews might be rated as helpful; rather than strengthening customer attitudes or purchase intentions, tentativeness weakens both.

Tentative reviews primarily affect consumer outcomes by weakening confidence in information completeness. When consumers perceive a deficit in information, one course of action is to seek for more information. For products with many reviews, this desire for more complete information may be satisfied by seeking other reviews. However, for products with fewer reviews and therefore very little extra information, the negative consequences may be 
more severe. As such, while our findings are relevant for all types of products, firms that exist in the 'long tail' need to be particularly attentive to tentative reviews. For such firms, the effort often devoted to monitoring negative and mixed reviews would need to be similarly applied to tentative reviews. The timing of the provision of tentative reviews is also important. Brand owners need to be particularly attentive when a product is new as tentative reviews among early reviews may potentially slow down its acceptance.

Our findings also show that tentative reviews are more influential when consumers have relatively weaker product experience. It follows then that it is important for marketers to distinguish between expert and novice consumers. There are product and service contexts where most of the prospective customers are novices and others where the average consumer possesses a high level of product experience or expertise. For instance, Nam et al (2012) highlight the point-and-shoot digital camera market, as one where most consumers are novices, compared to the DSLR market, where consumers are, on average, more sophisticated. In situations, where most customers have low product experience, compared to contexts where consumers have high product expertise, firms would need to pay significantly more attention to the management of tentative reviews. Our findings about how perceptions of a reviewer's expertise shape the effect of a tentative review are also managerially relevant as firms can incorporate this knowledge in designing strategies to mitigate the effects of tentative reviews.

Overall, therefore, our findings suggest a need for firms to actively respond to tentative reviews. Although many firms already monitor and respond to reviews, in our search through review sites, we find that firms may be unaware of the subtle but very real effect of tentative 
reviews. Brand owners prefer to respond to very positive and very negative reviews; we did not find any example of a response to a tentative review.

We suggest some potential forms these responses might take. First, firms can respond directly to a tentative review to explicitly assure the reviewer and readers (perhaps by providing evidence) that the positive evaluations in the review are sustainable in the long term. Such responses can also include links to extra information to enhance customers confidence in the information about the product. Perhaps an even more effective response to a tentative review is to ask the tentative reviewer to post a follow-up review, i.e., share more of their experience with the product after some more time has elapsed. There is some evidence that certain sites already ask reviewers to update their reviews even though such actions often focus on negative or mixed reviews. However, given the effects we find in this study, similar attention needs to focus on tentative reviews. Potentially, therefore, responding to a tentative review can serve as a vehicle for both initiating conversations with the tentative reviewer and charting their product-use journey for the benefit of other consumers.

Firms might also consider actions to reduce the occurrence of tentative reviews. While some consumers review products without being prompted, many reviews derive from requests by firms (Picazo-Vela et al., 2010). Although, not assessed this in this study, a plausible reason for tentativeness may be limited product use before providing the review. Given that tentative reviews reduce rather than enhance attitude certainty and purchase intentions, firms might consider striking a balance between generating quicker reviews and delaying requests for reviews to minimise the occurrence of tentative reviews. 
Beyond implications for marketers, our results may also have some broader consumer welfare implications. In academic and scientific discourse, it is normal for commentators to explicitly express tentativeness. This affects how information users interpret their claims and findings. Expressing tentativeness is less common in marketing environments. Nevertheless, it is possible that some claims by consumers (and even marketers), without any explicit expressions of tentativeness, may be inherently tentative. To the extent that some consumers may be unaware of this inherent tentativeness, they may make suboptimal decisions. In certain consumption contexts, e.g., advertising or information provision on social media, the appropriate expression of tentativeness by information providers may have significantly stronger consumer welfare implications. Clearly, therefore, training consumers to detect tentativeness, even in the absence of explicit tentative markers, can improve their decisionmaking. Furthermore, since consumers respond to explicit expressions of tentativeness, one way to protect consumers may be for policy makers, regulators and moderators of marketing content to urge or require information providers or commentators to, (when appropriate), incorporate tentativeness in their claims. Potentially, therefore, tentativeness may serve as one, among other characteristics of information, that could be used in specific contexts to assess the integrity of marketers' communication with consumers.

\section{Limitations and Future Research}

Although the findings in this study were robust to multiple changes in procedure, product type and sample characteristics, it is not without some limitations. A key limitation is that we examined the impact of tentative reviews in relatively small review sets. Although, consumers might still display a sensitivity to tentative reviews when review volume is greater, we did not test this directly. Past research has revealed that individual reviews are 
more influential when other means of information are scarce and review volume is low (Zhu and Zhang, 2010). It is likely that the effect we demonstrate will strongest in such situations.

In terms of our constructs, expertise was assessed using self-claims. Testing whether similar effects hold when expert status derives from peer ratings is one future research avenue. Furthermore, testing other outcomes of tentativeness and associated moderating effects can improve our understanding of the tentative review effect. For instance, personality variables such as the need for cognition and the need for cognitive closure may play a role in how and whether consumers process information. Moreover, product characteristics might also moderate some of the effects we address. For instance, are there product types for which where consumers infer that reviews are inherently tentative and thus are less likely to be sensitive to expressed tentativeness? Future research should also address what other product characteristics might be more strongly associated with the provision of tentative reviews.

In this study, we focused on instances where tentativeness is explicitly expressed. However, even when tentativeness is not explicitly expressed, observers of reviews might make judgements about the tentativeness of a review. Future studies can identify what other cues consumers might use to make these judgements. A final question that emanates from our research is: Why do people provide tentative reviews? Our research is focused exclusively on how tentative reviews affect the attitude certainty of those who read the reviews. We do not explore why some reviewers provide tentative reviews or what individual factors make tentative reviews more or less likely to be provided. These questions relate fundamentally to consumers' motivations for providing product reviews. We leave these issues for further research and hope our findings stimulate more interest in this important practical topic. 


\section{REFERENCES}

Ajzen, Icek. (1991), “The Theory of Planned Behavior”, Organizational Behavior and Human Decision Processes 50, 2 179-211.

Alba, Joseph W., and J. Wesley Hutchinson, (1987), "Dimensions of Consumer Expertise." Journal of Consumer Research, 13, 4 411-454.

Babić Rosario, Ana, Francesca Sotgiu, Kristine De Valck, and Tammo HA Bijmolt. (2016), "The Effect of Electronic Word-Of-Mouth on Sales: A Meta-Analytic Review of Platform, Product, and Metric Factors." Journal of Marketing Research, 53, 3 297-318.

Banerjee, Shankhadeep, Samadrita Bhattacharyya, and Indranil Bose (2017), "Whose Online Reviews to Trust? Understanding Reviewer Trustworthiness and its Impact on Business", Decision Support Systems, 96, 17-26.

Bhattacherjee, Anol. and Clive Sanford, (2006) "Influence Processes for Information Technology Acceptance: An Elaboration Likelihood Model," MIS Quarterly, 30, 4 805-825.

Burgoon, Judee, William J. Mayew, Justin Scott Giboney, Aaron C. Elkins, Kevin Moffitt, Bradley Dorn, Michael Byrd, and Lee Spitzley (2016), Which Spoken Language Markers Identify Deception in High-Stakes Settings? Evidence from Earnings Conference Calls. Journal of Language and Social Psychology, 35, 2 123-157.

Cacioppo, John T., and Richard E. Petty (1982), "The Need for Cognition." Journal of Personality and Social Psychology 42, 1116.

Casaló, Luis V., Carlos Flavián, Miguel Guinalíu, and Yuksel Ekinci (2015). “Avoiding the Dark Side of Positive Online Consumer Reviews: Enhancing Reviews' Usefulness for High Risk-Averse Travelers”, Journal of Business Research, 68, 9 1829-1835.

Chevalier, Judith A., Yaniv Dover, and Dina Mayzlin (2018), "Channels of Impact: User Reviews When Quality is Dynamic and Managers Respond." Marketing Science, 37, 5 688709. 
Chiou, Jyh-Shen, Cheng-Chieh Hsiao, and Tien-Yi Chiu (2018). The Credibility and Attribution of Online Reviews: Differences Between High and Low Product Knowledge Consumers. Online Information Review, 42, 5 630-646.

Choi, Sungwoo, and Anna S. Mattila (2018), "The Effect of Experience Congruity on Repurchase Intention: The Moderating Role of Public Commitment." Service Science 10, 2 124-138.

Feinkohl, Insa, Danny Flemming, Ulrike Cress, and Joachim Kimmerle (2016), “The Impact of Personality Factors and Preceding User Comments on the Processing of Research Findings on Deep Brain Stimulation: A Randomized Controlled Experiment in a Simulated Online Forum". Journal of Medical Internet Research, 18, 3 e59.

Flemming, Danny., Insa Feinkohl, Ulrike Cress, and Joachim Kimmerle (2015). Individual Uncertainty and the Uncertainty of Science: The Impact of Perceived Conflict and General Self-Efficacy on The Perception of Tentativeness and Credibility of Scientific Information, Frontiers in Psychology, 6, 1859.

Flemming, D., Ulrike Cress., \& Joachim Kimmerle (2017), “User Comments about Research Findings: How Conflictual Information in Online Science Journalistic Articles Influences Laypeople's Understanding of Scientific Tentativeness", Communications, 42, 4 465-480.

Floyd, Kristopher, Ryan Freling, Saad Alhoqail, Hyun Young Cho, and Traci Freling (2014): "How Online Product Reviews Affect Retail Sales: A Meta-Analysis." Journal of Retailing, $90,2217-232$.

Folse, Judith Anne Garretson, McDowell Porter III, Mousumi Bose Godbole, and Kristy E. Reynolds (2016). "The Effects of Negatively Valenced Emotional Expressions in Online Reviews on The Reviewer, The Review, And the Product”, Psychology \& Marketing, 33, 9 747-760. 
Forbes-Riley, Kate, and Diane Litman (2011), "Benefits and Challenges of Real-Time Uncertainty Detection and Adaptation in a Spoken Dialogue Computer Tutor”, Speech Communication, 53, 9-10, 1115-1136.

Forman, Chris, Anindya Ghose, and Batia Wiesenfeld (2008), "Examining the Relationship Between Reviews and Sales: The Role of Reviewer Identity Disclosure in Electronic Markets", Information Systems Research, 19, 3 291-313.

Häfner, Michael, and Debra Trampe (2009), "When Thinking Is Beneficial And When It Is Not: The Effects of Thin and Round Advertising Models." Journal of Consumer Psychology 19, 4, 619-628.

Hair, Michael and Timucin Ozcan (2018). "How Reviewers' Use of Profanity Affects Perceived Usefulness of Online Reviews." Marketing Letters 29, 2 151-163.

Hassan, Safwat, Chakkrit Tantithamthavorn, Cor-Paul Bezemer, and Ahmed E. Hassan. (2018), "Studying the Dialogue Between Users and Developers of Free Apps in the Google Play Store." Empirical Software Engineering, 23, 3, 1275-1312.

Hayes, Andrew F.(2013), "Introduction to Mediation, Moderation, and Conditional Process Analysis: A Regression-Based Approach”. New York, NY: The Guilford Press

Ho-Dac, Nga N., Stephen J. Carson, and William L. Moore, (2013), “The Effects of Positive and Negative Online Customer Reviews: Do Brand Strength and Category Maturity Matter?" Journal of Marketing, 77,6, 37-53.

Jensen, Matthew L., Joshua M. Averbeck, Zhu Zhang, and Kevin B. Wright (2013), "Credibility of Anonymous Online Product Reviews: A Language Expectancy Perspective". Journal of Management Information Systems, 30, 1, 293-324.

Jiménez, Fernando R., and Norma A. Mendoza (2013), “Too Popular to Ignore: The Influence of Online Reviews on Purchase Intentions of Search and Experience Products" Journal of Interactive Marketing, 27, 3, 226-235. 
Kardes, Frank R., Steven S. Posavac, and Maria L. Cronley. (2004), Consumer Inference: A Review of Processes, Bases, and Judgment Contexts, Journal of Consumer Psychology, 14, 3, $230-256$.

Kardes, Frank R., Steven S. Posavac, David Silvera, Maria L. Cronley, David M.

Sanbonmatsu, Susan Schertzer, Felicia Miller, Paul M. Herr, and Murali Chandrashekaran, (2006), “Debiasing Omission Neglect”. Journal of Business Research, 59, 6, 786-792.

Karmarkar, Uma R., and Zakary L. Tormala, (2009) "Believe Me, I Have No Idea What I'm Talking About: The Effects of Source Certainty on Consumer Involvement and Persuasion." Journal of Consumer Research 36, 6, 1033-1049.

Kim, J., \& Gupta, P. (2012), "Emotional Expressions in Online User Reviews: How They Influence Consumers' Product Evaluations”. Journal of Business Research, 65, 7, 985-992.

King, Robert Allen, Pradeep Racherla, and Victoria D. Bush, (2014), "What We Know and Don't Know About Online Word-Of-Mouth: A Review and Synthesis of The Literature", Journal of Interactive Marketing, 28, 3, 167-183.

Koçaş, Cenk, and Can Akkan, (2016), "A System for Pricing the Sales Distribution from Blockbusters to The Long Tail", Decision Support Systems, 89 56-65.

Lederman, Norman G., and Molly O'Malley (1990), "Students' Perceptions of Tentativeness in Science: Development, Use, And Sources of Change." Science Education 74, 2, 225-239.

Lee, SeungHyun, and Heejung Ro (2016), “The Impact of Online Reviews on Attitude Changes: The Differential Effects of Review Attributes and Consumer Knowledge" International Journal of Hospitality Management, 56, 1-9.

Ludwig, Stephan, Ko De Ruyter, Mike Friedman, Elisabeth C. Brüggen, Martin Wetzels, and Gerard Pfann (2013), "More Than Words: The Influence of Affective Content and Linguistic Style Matches in Online Reviews on Conversion Rates”. Journal of Marketing, 77, 1, 87-103. 
Mason, Kevin, Thomas Jensen, Scot Burton, and Dave Roach (2001), "The Accuracy of Brand and Attribute Judgments: The Role of Information Relevancy, Product Experience, and Attribute-Relationship Schemata" Journal of the Academy of Marketing Science, 29, 3, 308-318.

McAuley, Julian, Rahul Pandey, and Jure Leskovec (2015), "Inferring networks of substitutable and complementary products." In Proceedings of the 21th ACM SIGKDD international conference on knowledge discovery and data mining, 785-794. ACM.

McGinnies, Elliott, and Charles D. Ward (1980), "Better Liked Than Right: Trustworthiness and Expertise as Factors in Credibility" Personality and Social Psychology Bulletin, 6, 3, 467-472.

Minnema, Alec, Tammo HA Bijmolt, Sonja Gensler, and Thorsten Wiesel (2016), “To Keep or Not to Keep: Effects of Online Customer Reviews on Product Returns", Journal of Retailing, 92, 3, 253-267.

Mitchell, Andrew A., and Peter A. Dacin (1996), “The Assessment of Alternative Measures of Consumer Expertise”, Journal of Consumer Research, 23, 3, 219-239.

Moore, Sarah. G. (2015), “Attitude Predictability and Helpfulness in Online Reviews: The Role of Explained Actions and Reactions”. Journal of Consumer Research, $42,1,30-44$.

Mudambi, Susan M., and David Schuff (2010), "What Makes a Helpful Review? A Study of Customer Reviews on Amazon.Com”. MIS quarterly, 34, 1, 185-200.

Nam Myungwoo, Jing Wang, and Angela Y. Lee (2012), "The Difference Between Differences: How Expertise Affects Diagnosticity of Attribute Alignability." Journal of Consumer Research: 39, 4, 736-750

Petty, Richard E., and Pablo Brinol, (2008), "Persuasion: From Single to Multiple to Metacognitive Processes" Perspectives on Psychological Science, 3, 2, 137-147. 
Pfeiffer, Bruce E., Hélène Deval, Frank R. Kardes, Douglas R. Ewing, Xiaoqi Han, and Maria L. Cronley (2014), "Effects of Construal Level on Omission Detection and Multiattribute Evaluation”, Psychology and Marketing, 31, 11, 992-1007.

Picazo-Vela, Sergio, Shih Yung Chou, Arlyn J. Melcher, and John M. Pearson, (2010), "Why Provide an Online Review? An Extended Theory of Planned Behavior and the Role of BigFive Personality Traits", Computers in Human Behavior, 26, 4, 685-696.

Poddar, Amit, Syagnik Banerjee, and Karthik Sridhar (2017), "False Advertising or Slander? Using Location Based Tweets to Assess Online Rating-Reliability." Journal of Business Research, 99, 390-397

Preacher, Kristopher J., Derek D. Rucker, and Andrew F. Hayes, (2007). "Addressing Moderated Mediation Hypotheses: Theory, Methods, and Prescriptions." Multivariate Behavioral Research, 42, 1, 185-227.

Qiu, Lingyun, Jun Pang, and Kai H. Lim (2012), "Effects of Conflicting Aggregated Rating on EWOM Review Credibility And Diagnosticity: The Moderating Role of Review Valence”, Decision Support Systems, 54, 1, 631-643.

Rucker, Derek D., Zakary L. Tormala, Richard E. Petty, and Pablo Briñol (2014), “Consumer Conviction and Commitment: An Appraisal-Based Framework for Attitude Certainty" Journal of Consumer Psychology, 24, 1, 119-136.

Rucker, Derek D. and Richard E. Petty (2004), "When Resistance Is Futile: Consequences of Failed Counterarguing for Attitude Certainty," Journal of Personality and Social Psychology, $86,2,219-35$.

Schlosser, Ann. E. (2011), "Can Including Pros and Cons Increase the Helpfulness and Persuasiveness of Online Reviews? The Interactive Effects of Ratings and Arguments. Journal of Consumer Psychology, 21,3, 226-239. 
Schwartz, Renee, and Norman Lederman, (2008) "What Scientists Say: Scientists' Views of Nature of Science and Relation to Science Context." International Journal of Science Education 30, 6, 727-771.

Sen, Shahana, and Dawn Lerman (2007), "Why Are You Telling Me This? An Examination into Negative Consumer Reviews on the Web", Journal of Interactive Marketing, 21, 4, 7694.

Snehasish, Banarjee. (2017). Study of Authentic and Fictitious Online Reviews (Unpublished Doctoral dissertation).

Sheppard, Blair H., Jon Hartwick, and Paul R. Warshaw (1988), "The Theory of Reasoned Action: A Meta-Analysis of Past Research with Recommendations for Modifications and Future Research", Journal of Consumer Research, 15, 3, 325-343.

Shoham, Meyrav, Sarit Moldovan, and Yael Steinhart (2017), "Positively Useless: Irrelevant Negative Information Enhances Positive Impressions", Journal of Consumer Psychology, 27, 2, 147-159.

Skowronski, John J., and Donal E. Carlston (1989), "Negativity and Extremity Biases in Impression Formation: A Review of Explanations", Psychological Bulletin, 105, 1, 131-142

Smith, S. M., Fabrigar, L. R., MacDougall, B. L., \& Wiesenthal, N. L. (2008), “The Role of Amount, Cognitive Elaboration, and Structural Consistency of Attitude-Relevant Knowledge in the Formation of Attitude Certainty", European Journal of Social Psychology, 38, 2, 280 295.

Tang, Tanya, Eric Fang, and Feng Wang (2014), "Is Neutral Really Neutral? The Effects of Neutral User-Generated Content on Product Sales”, Journal of Marketing, 78, 4, 41-58.

Taylor, Shelley E., and Suzanne C. Thompson (1982), "Stalking the Elusive Vividness Effect”, Psychological Review, 89, 155-181. 
Tormala, Zakary L., and Derek D. Rucker. (2018), “Attitude Certainty: Antecedents, Consequences, and New Directions”, Consumer Psychology Review, 1,1, 72-89.

Wan, Echo Wen, Derek D. Rucker, Zakary L. Tormala, and Joshua J. Clarkson (2010), "The Effect of Regulatory Depletion on Attitude Certainty." Journal of Marketing Research 47, 3, $531-541$.

Webster, Donna M., and Arie W. Kruglanski, (1994), "Individual Differences in Need for Cognitive Closure." Journal of Personality and Social Psychology 67, 6 (1994): 1049.

Willemsen, Lotte M., Peter C. Neijens, and Fred Bronner (2012), "The Ironic Effect of Source Identification on the Perceived Credibility of Online Product Reviewers", Journal of Computer-Mediated Communication, 18, 1, 16-31.

Wu, Laurie, Han Shen, Mimi Li, and Qian Deng (2017), "Sharing Information Now Vs Later: The Effect of Temporal Contiguity Cue and Power on Consumer Response Toward Online Reviews." International Journal of Contemporary Hospitality Management 29, 2, 648-668.

Xie, Hui Jimmy, Li Miao, Pei-Jou Kuo, and Bo-Youn Lee (2011), “Consumers' Responses to Ambivalent Online Hotel Reviews: The Role of Perceived Source Credibility and PreDecisional Disposition”. International Journal of Hospitality Management, 30,1, 178-183.

Yin, Dezhi, Samuel Bond, and Han Zhang (2014), “Anxious or Angry? Effects of Discrete Emotions on The Perceived Helpfulness of Online Reviews. MIS Quarterly, 38, 2, 539-560

Zhu, Feng, and Xiaoquan Zhang (2010), "Impact of Online Consumer Reviews on Sales: The Moderating Role of Product and Consumer Characteristics”, Journal of Marketing, 74, 2, $133-148$. 


\section{APPENDICES}

Appendix A. Analysis of online reviews

1. Prevalence of Tentative Reviews by Product Category

\begin{tabular}{|l|l|l|l|l|l|}
\hline Category & Website & $\begin{array}{l}\text { Average Number of } \\
\text { Reviews per } \\
\text { product }\end{array}$ & \multicolumn{2}{l|}{$\begin{array}{l}\text { Number of tentative } \\
\text { reviews per product } \\
\text { category }\end{array}$} & $\begin{array}{l}\text { \% of tentative } \\
\text { reviews }\end{array}$ \\
\hline Dishwasher (Beko) & Ao.com & 303 & Mean & Median & \\
\hline Camera Drone & Currys & 66 & 17 & 9 & $5.6 \%$ \\
\hline Wireless (charger & Amazon & 243 & 3 & 2 & $4.5 \%$ \\
(Belkin) & & & 9 & 5 & $3.7 \%$ \\
\hline Overall & & & & & \\
\hline
\end{tabular}

We conducted this analysis to investigate the likelihood of consumers encountering tentative online reviews in the marketplace. Because aggregate review characteristics (volume, display options etc) differ among review websites, we collected data from three different websites.

We obtained review data for the top 3 most popular items for a specific mid-range brand in 2 of the four categories represented in our studies (dishwashers and wireless chargers). For drones, we selected three products with the highest number of reviews and overall scores of more than 4 out of 5 . 
We recruited 3 undergraduate students and provided them with the definitions of tentative reviews used in this research. They then answered a comprehension item to ensure they had read and understood the definition. The students read through all the reviews on the review sites and copied out all the reviews they considered to be tentative. We collated their results and then counted the number of reviews for which there was agreement among the four students. Where there was no perfect agreement, we did not consider these reviews as tentative.

This analysis indicates that consumers do encounter tentative reviews in the marketplace; these in turn could lead to the effect identified in this study. While the percentage of tentative reviews is quite small, previous studies on review characteristics have found similar levels of prevalence of the characteristics they study. For instance, Shoham et al (2017) in a similar study of how an additional review (in this case an irrelevant negative review) affects consumer attitudes and choices, found out that less than four percent of reviews had the characteristic (irrelevance) they were interested in. Chen and Lurie's study on temporal contiguity also found that $3.7 \%$ of reviews contained temporal contiguity cues. Furthermore, in a study of how the use of profanity influences consumers, Hair et al (2018), found out that only about $3 \%$ of reviews contained profanity.

\section{Tentative Reviews over Time}

We expected that newer product types might receive more tentative reviews than more established categories. Our analysis, however, showed that the dishwasher (an established product category) had the largest percentage of tentative reviews. To gain further insight, we tested the pattern of provision of tentative reviews over time; we surmised that among the earliest reviews for a product, newer product types might contain a larger percentage of tentative reviews compared to more established categories. In other words, as new product 
categories become established and general product expertise increases; tentative reviews might be less likely to be provided. For more established categories, the rate of provision might be more even over time. To test this prevalence of tentative reviews over time, we compared the first 100 reviews provided for the most popular dishwasher and wireless charger in our data set.

\begin{tabular}{|l|l|l|}
\hline Product & \multicolumn{2}{|c|}{ Number and Percentage of Tentative Reviews } \\
\hline & In overall sample & In the subset \\
\hline Dishwasher & $33 / 556(5.93 \%)$ & $7 / 100(7 \%)$ \\
\hline Wireless charger & $18 / 390(4.6 \%)$ & $10 / 100(10 \%)$ \\
\hline
\end{tabular}

The pattern fits with our assumptions. Tentative reviews were on average more prevalent in the earlier than in latter group of reviews. $10 \%$ of the early reviews for the wireless charger were tentative compared to $7 \%$ for the dishwasher. The rate of provision of tentative reviews was also more even over the full range of reviews for the dishwasher than the wireless charger.

\section{Tentativeness and Review Helpfulness}

Finally, we evaluated how tentativeness was related to review helpfulness by comparing results for positive, mixed, negative and tentative reviews. We chose another product on Amazon (Narkosite anti-bark dog collar) for this analysis because it had a better variation of positive, mixed and negative reviews than products in the previous sample. The chosen product had a total number of 526 reviews. The findings are contained in the two tables below. 


\begin{tabular}{|l|l|l|l|l|l|l|}
\hline \multirow{2}{*}{} & \multicolumn{7}{|c|}{ Star Rating of Review } \\
\cline { 2 - 8 } & $1 *$ & $2 *$ & $3^{*}$ & $4 *$ & $5 *$ & Total \\
\hline Total number of reviews & 91 & 33 & 34 & 60 & 308 & 526 \\
\hline Percentage of reviews & $17.30 \%$ & $6.27 \%$ & $6.46 \%$ & $11.40 \%$ & $58.55 \%$ & $100 \%$ \\
\hline Number of helpful reviews & 21 & 2 & 4 & 7 & 54 & 88 \\
\hline Percentage of helpful reviews & $23.86 \%$ & $2.27 \%$ & $4.54 \%$ & $7.95 \%$ & $61.36 \%$ & 100 \\
\hline
\end{tabular}

\begin{tabular}{|l|l|l|l|l|l|}
\hline & \multicolumn{5}{|c|}{ Type of Review } \\
\hline & Negative & Mixed & Positive & Tentative & Total \\
\hline Total number of reviews & 91 & 66 & 347 & 22 & 526 \\
\hline Percentage of reviews by type & $17.30 \%$ & $12.54 \%$ & $65.96 \%$ & $4.2 \%$ & $100 \%$ \\
\hline Number of helpful reviews & 19 & 10 & 48 & 10 & 87 \\
\hline Percentage of helpful reviews & $21.83 \%$ & $11.5 \%$ & $55.17 \%$ & $11.5 \%$ & $100 \%$ \\
\hline $\begin{array}{l}\text { Average number of votes per } \\
\text { helpful review }\end{array}$ & 1.36 & 1.5 & 3.62 & 5 & \\
\hline
\end{tabular}

The mean of helpful votes received for the tentative reviews is significantly different from that of the negative $(t=2.73)$ and mixed reviews $(t=2.01)$ but, while higher, is not significantly different from the mean of helpful votes received by the positive reviews $(t=$ 1.22). 
Appendix B

\begin{tabular}{|l|l|l|l|l|l|}
\hline \multicolumn{2}{|c|}{ Contrast Tests for Study 1: Attitude Certainty in Each Condition versus all other } \\
Conditions \\
\\
\cline { 2 - 7 } & $\begin{array}{l}\text { Value of } \\
\text { Contrast }\end{array}$ & Std Error & $\mathrm{t}$ & $\mathrm{df}$ & $\begin{array}{l}\text { Sig. (2- } \\
\text { tailed) }\end{array}$ \\
\hline Contrast & & & & & \\
\hline & -.4171 & .19590 & -2.129 & 151 & .035 \\
\hline Negative Review Condition & .6371 & .17318 & 3.679 & 151 & .000 \\
\hline Control Condition & .3754 & .16825 & 2.231 & 151 & .027 \\
\hline Positive Review Condition & -.7073 & .15580 & -4.540 & 151 & .000 \\
\hline Tentative Review Condition & & & & & \\
\hline
\end{tabular}

\begin{tabular}{|ll|c|c|}
\hline \multicolumn{3}{|c|}{ Study 1: Comparisons of Attitude Certainty Across all Conditions } \\
\hline \multirow{2}{*}{ (I) Condition } & (J) Condition & Mean Difference (I- & Sig. \\
\hline Positive (5.22) & Tentative & $.8328^{*}$ & .000 \\
& Negative & .6096 & .002 \\
& Control & -.1434 & .498 \\
\hline Tentative (4.39) & Positive & $-.8328^{*}$ & .000 \\
& Negative & -.2232 & .081 \\
& Control & $-.9763^{*}$ & .000 \\
\hline Negative (4.61) & Positive & -.6096 & .042 \\
& Tentative & .2232 & .081 \\
& Control & $-.7530^{*}$ & .016 \\
\hline Control (5.36) & Positive & .1434 & .921 \\
& Tentative & $.9763^{*}$ & .000 \\
& Neg & $.7530^{*}$ & 0.00 \\
\hline
\end{tabular}


Appendix C

Contrast Tests for Study 1b: Willingness to Purchase in Each Condition versus all other Conditions

\begin{tabular}{|c|c|c|c|c|c}
\hline Contrast & $\begin{array}{l}\text { Value of } \\
\text { Contrast }\end{array}$ & Std Error & $\mathrm{t}$ & $\mathrm{df}$ & $\begin{array}{c}\text { Sig. (2- } \\
\text { tailed) }\end{array}$ \\
\hline Control & .8667 & .20000 & 4.333 & 87 & .000 \\
\hline Mixed Review & -.0333 & .20000 & -.167 & 87 & .868 \\
\hline Tentative Review & -.8333 & .20000 & -4.167 & 87 & .000 \\
\hline
\end{tabular}

\begin{tabular}{|c|c|c|c|c|c|}
\hline \multicolumn{6}{|c|}{$\begin{array}{l}\text { Contrast Tests for Study } 1 \mathrm{~b} \text { : Confidence in Information Completeness in Each } \\
\text { Condition versus all other Conditions }\end{array}$} \\
\hline Contrast & $\begin{array}{l}\text { Value of } \\
\text { Contrast }\end{array}$ & Std Error & $\mathrm{t}$ & $\mathrm{df}$ & $\begin{array}{l}\text { Sig. (2- } \\
\text { tailed) }\end{array}$ \\
\hline Control & .3167 & .23692 & 1.337 & 87 & .185 \\
\hline Mixed Review & .2667 & .23692 & 1.126 & 87 & .263 \\
\hline Tentative Review & -.5833 & .23692 & -2.462 & 87 & .016 \\
\hline
\end{tabular}


Study 1b: Multiple Comparisons

\begin{tabular}{|c|c|c|c|c|c|}
\hline Dependent Variable & (I) Condition & $(\mathrm{J})$ Condition & $\begin{array}{c}\text { Mean } \\
\text { Difference (I- } \\
\mathrm{J}) \\
\end{array}$ & Std. Error & Sig. \\
\hline \multirow{6}{*}{$\begin{array}{c}\text { Willingness to } \\
\text { purchase }\end{array}$} & \multirow[t]{2}{*}{ Control } & Mixed Review & $.60000^{*}$ & .23094 & .011 \\
\hline & & $\begin{array}{l}\text { Tentative } \\
\text { Review }\end{array}$ & $1.13333^{*}$ & .23094 & .000 \\
\hline & \multirow[t]{2}{*}{ Mixed Review } & Control & $-.60000^{*}$ & .23094 & .011 \\
\hline & & $\begin{array}{l}\text { Tentative } \\
\text { Review }\end{array}$ & $.53333^{*}$ & .23094 & .023 \\
\hline & \multirow{2}{*}{$\begin{array}{l}\text { Tentative } \\
\text { Review }\end{array}$} & Control & $-1.13333^{*}$ & .23094 & .000 \\
\hline & & Mixed Review & $-.53333^{*}$ & .23094 & .023 \\
\hline \multirow{6}{*}{$\begin{array}{l}\text { Information } \\
\text { Completeness }\end{array}$} & \multirow[t]{2}{*}{ Control } & Mixed Review & .03333 & .27357 & .903 \\
\hline & & $\begin{array}{l}\text { Tentative } \\
\text { Review }\end{array}$ & $.60000^{*}$ & .27357 & .031 \\
\hline & \multirow[t]{2}{*}{ Mixed Review } & Control & -.03333 & .27357 & .903 \\
\hline & & $\begin{array}{l}\text { Tentative } \\
\text { Review }\end{array}$ & $.56667^{*}$ & .27357 & .041 \\
\hline & \multirow{2}{*}{$\begin{array}{c}\text { Tentative } \\
\text { Review }\end{array}$} & Control & $-.60000^{*}$ & .27357 & .031 \\
\hline & & Mixed Review & $-.56667^{*}$ & .27357 & .041 \\
\hline
\end{tabular}




\section{APPENDIX D - STIMULI}

\section{DISHWASHER REVIEWS}

\section{$\underline{\text { Reviews common to all conditions }}$}

1. Machine exactly what we needed. Easy to install, quiet when on, quick wash, great for a small wash.

2. I am delighted with my new dishwasher. It looks great in my kitchen, it has a good variety of wash settings and my dishes come out sparkling.

3. Full marks for this dishwasher. I am so pleased with it - I cannot fault it. Would highly recommend to anyone thinking of purchasing a dishwasher.

4. Easy to install. Quiet dishwasher with 5 different programmes. Would recommend

\section{Additional Reviews}

5. Does a very good job for the money (Additional Positive)

6. Does a very good job for the money. Too early to say how good it really is (Tentative Review 1)

7. Does a very good job for the money. We'll have to wait and see how good it really is (Tentative Review 2)

8. I only used it once and it broke down. Does not wash or dry, a horrible humming noise when on. Very poorly designed. Would not recommend to my enemy (Negative Review)

\section{RESTAURANT REVIEWS}

$\underline{\text { Reviews common to all conditions }}$

1. My family had a wonderful dinner here. Food was exceptional, couldn't fault anything from delicious food, great presentation to friendly and attentive service. We even met the talented chef! Do try!

2. We ate with a group of 8 and the service was excellent. Really warm and relaxed atmosphere. Great food, wine and cocktails.

3. Lovely setting, great food and well presented. Staff very friendly and accommodating. Reasonable price for a meal, and good selection to choose from. Will definitely be back again, would recommend.

4. Great service all very attentive and smiley faces all around. I would recommend this restaurant to my friends and family.

\section{$\underline{\text { Additional Reviews }}$}


5. Looks lovely, table was set nicely and atmosphere was welcoming. The service was exceptional, and the food was good. (Additional Positive Review)

6. Looks lovely, table was set nicely and atmosphere was welcoming. Although the service was exceptional, I was a bit disappointed with the food. Some dishes were too small, others they tried too hard (Mixed Review)

7. Looks lovely, table was set nicely and atmosphere was welcoming. The service was exceptional, and the food was good. However, it is too early to say how good this restaurant really is (Tentative Review)

\section{CAMERA DRONE REVIEWS}

\section{$\underline{\text { Reviews Common to all conditions }}$}

1. Excellent camera quality, very good stability and some pretty unique features that I've found very useful (much more than I supposed initially!) like zooming and camera uptilt. I can only say that it is a great drone.

2. Excellent drone. Smooth flyer and excellent gimbal. Easy to use software

3. Excellent drone for the price range.

4. This is a great drone. Does exactly what is expected and at a good price.

\section{$\underline{\text { Additional Reviews }}$}

5. As someone who is using a drone for the first time, all I can say is the drone has an amazing camera both in stills and video. It is easy to fly. Compact, so easy to carry and take anywhere. However, it's too early to say how reliable this smart camera drone is in the long term (Tentative Novice Condition)

6. The drone has an amazing camera both in stills and video. It is easy to fly. Compact, so easy to carry and take anywhere. However, it's too early to say how reliable this smart camera drone is in the long term (Tentative No Source Information Condition)

7. As someone who is using a drone for the first time, all I can say is the drone has an amazing camera both in stills and video. It is easy to fly. Compact, so easy to carry and take anywhere. (Non-tentative Novice Condition)

8. The drone has an amazing camera both in stills and video. It is easy to fly. Compact, so easy to carry and take anywhere. (Non-tentative No Source Information Condition) 


\section{WIRELESS CHARGER REVIEWS}

\section{$\underline{\text { Reviews Common to Both Conditions }}$}

1. Great product! Works as soon as I place the phone on it. Packaging says that it won't charge if the phone has a case and to remove it, but I leave mine on and it 'fast charges' my phone, unlike my previous charger. Glad I purchased it.

2. This looks excellent quality, the indicator light is dim ideal at night. I haven't noticed any heat while charging. The cable is a good length. Charging time is acceptable

3. It's a bit smaller than i expected but it looks very nice. Slim, minimalistic with a subtle led indicator.

4. Fantastic wireless charging pad. I get into work in the morning, throw my phone on it and leave it to charge. The surface is grippy so my phone doesn't slide off. Would definitely recommend

\section{Additional Reviews}

5. Works very well. Looks very good and the charge time is faster than expected. (Additional Positive Review)

6. Works very well. Looks very good and the charge time is faster than expected. Too early to say how it would hold up. (Tentative Review) 